\title{
PEMBEKALAN DAN IMPLEMENTASI PEMBELAJARAN ABAD 21 BAGI GURU BAHASA INGGRIS SMP KABUPATEN SUMEDANG
}

\author{
Aam Ali Rahman ${ }^{1}$, Anggi Setia Lengkana ${ }^{2}$, Anggi Angraeni ${ }^{3}$ \\ 1,2, Jurusan PGSD Penjas, Universitas Pendidikan Indonesia \\ ${ }^{3}$ SMP Negeri 1 Sukasari, Sumedang \\ e-mail: alirahman@upi.edu
}

\begin{abstract}
Abstrak
Pengabdian ini memberikan penguatan untuk guru-guru Bahasa Inggris di Sumedang, Jawa Barat. Penguatan yang diberikan berupa Keterampilan Abad 21 yang mencakup Kualitas Karakter Siswa (Religiositas, Nasionalisme, Kemandirian, Gotong royong, dan Integritas), Keterampilan Literasi Dasar (Bahasa, Numerasi, Sains, Digital, Finansial, serta Budaya dan Kewarganegaraan), serta Kompetensi (Berpikir kritis, Kreativitas, Komunikasi dan Kolaborasi) yang harus dimiliki pendidik. Penguatan ini berhasil menguatkan keterampilan Abad 21 para guru mata pelajaran Bahasa Inggris. Sebanyak 30 guru Bahasa Inggris yang tergabung di Musyawarah Guru Mata Pelajaran (MGMP) jenjang SMP di Kabupaten Sumedang mengikuti penguatan ini. Materi yang disampaikan mencakup penyusunan rencana pembelajaran Berbasis Keterampilan, Pelaksanaan Pembelajaran, serta Evaluasi Pembelajaran termasuk penilaian Abad 21 dengan memberikan pelatihan dan pendampingan. Dari ke-4 materi yang disampaikan tingkat kebermanfaatan kegiatan berdasarkan hasil survey adalah $87 \%$ keatas.
\end{abstract}

Kata kunci: Bahasa Inggris, Keterampilan abad 21, Pendidikan Karakter

\begin{abstract}
This service provides reinforcement for English teachers in Sumedang, West Java. The reinforcement provided is in the form of 21st Century Skills, which include the Quality of Student Character (Religiosity, Nationalism, Independence, Mutual Cooperation, and Integrity), Basic Literacy Skills (Language, Numeracy, Science, Digital, Financial, and Culture and Citizenship), and Competence (Thinking). Critical, Creativity, Communication and Collaboration) that must be owned by educators. This service has succeeded in strengthening the 21st Century skills of 30 English teachers who are members of the Junior High School Subject Teacher Group (MGMP) in Sumedang. The material presented includes preparing Skill-Based learning plans, Learning Implementation, and Learning Evaluation, including 21st Century assessment by providing training and mentoring. Of the four materials presented, the level of effectiveness of activities based on survey results is $87 \%$ and above.
\end{abstract}

Keywords: English, $21^{\text {st }}$ Century Skills, Character Education. 


\section{PENDAHULUAN}

Seiring perkembangan jaman, tuntutan bagi pelaku jaman pun berkembang. Pada abad 21, manusia dituntut untuk dapat menjawab tantangan jaman berupa globalisasi di segala bidang. Dengan kata lain, Abad 21 ditandai dengan kondisi-kondisi berikut: (1) informasi tersedia dimana saja dan dapat diakses kapan saja; (2) komputasi semakin cepat; (3) otomasi menggantikan pekerjaan-pekerjaan rutin; dan (4) komunikasi dapat dilakukan dari mana saja dan kemana saja (Kemdikbud, 2013).

Secara menyeluruh, abad 21 juga dikenal sebagai masa pengetahuan (Knowledge age), dimana perubahan untuk mempersiapkan diri dalam menghadapi tuntutan hidup dan bekerja sangat diperlukan, terutama dalam bidang Pendidikan. Secara sederhana, pengaplikasian dan penggunaan teknologi dalam proses pembelajaran baik itu di kelas ataupun di luar kelas merupakan suatu kebutuhan (Simin et al., 2014). Dalam garis besar pembangunan nasional Indonesia, Pendidikan merupakan salah satu usaha dalam mensejahterakan kehidupan manusia. Sehingga, ketika kehidupan manusia bergeser ke knowledge age, maka Pendidikan juga seharusnya menyesuaikan.

Namun merubah mindset para pelaku pendidikan untuk segera berkembang ke knowledge age bukan hal yang mudah. Perubahannya yang sangat besar dan mendasar yang dimulai dari sistem pendidikan nasional ke sistem pengajaran. Warisan pendidikan yang masih menganut sistem pendidikan lama yang masih menganut sistem menghafal informasi tanpa mampu menganalisis dan mengimplementasikan dalam kehidupan sehari-hari masih digunakan.

Dalam konsep perubahan sistem Pendidikan di Indonesia, telah dirusmuskan lima framework pembelajaran (BNSP, 2010). Kemampuan tersebut mencakup: Critical-Thinking and Problem-Solving Skills; Communication and Collaboration Skills; Creativity and Innovation Skills; Information and Communication Technology Literacy; Contextual Learning Skills. Hal tersebut juga dipertegas dengan temuan dimana kemampuan berfikir kritis, literasi digital, informasi, media, serta mampu menguasai teknologi informasi dan komunikasi merupakan kemampuan yang harus dimiliki seseorang untuk menghadapi pembelajaran abad 21 (Au, 2011).

Ketika siswa dituntut untuk memiliki kemampuan abad 21 untuk bekal hidup dan karir mereka di masa yang akan datang, maka sudah selayaknya guru, sebagai ujung tombak Pendidikan, telah memiliki kemampuan tersebut terlebih dahulu. Sehingga guru tersebut mampu melakukan inovasi pembelajaran dengan menggunakan media dan teknologi yang telah tersedia, guna membekali siswa didiknya untuk hidup dan karir. Seperti yang digambarkan dalam pelangi keterampilan pengetahuan abad 21 (Trilling \& Fadel, 2009). 


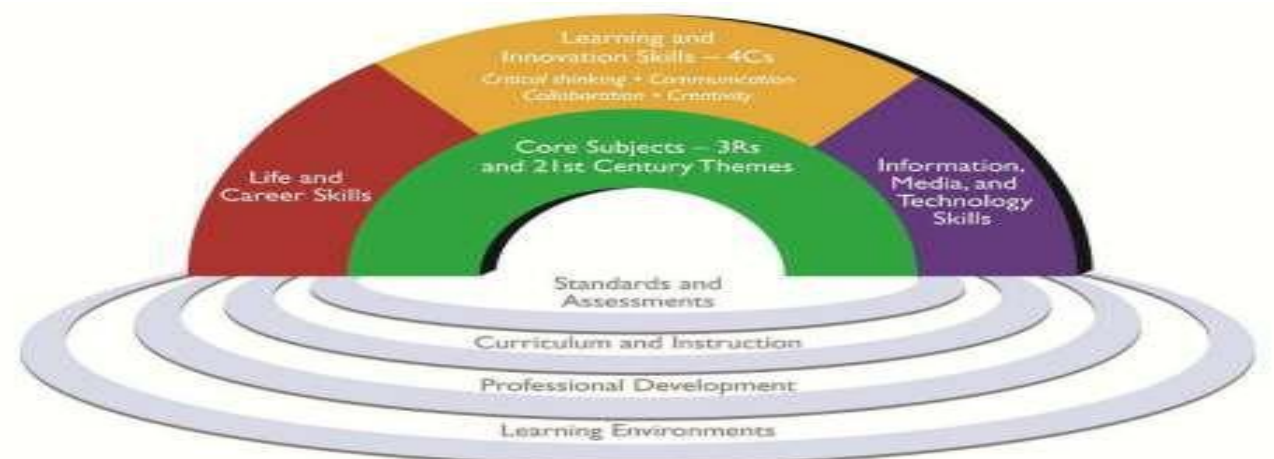

Gambar 1. Framework Pembelajaran Abad 21 (Trilling \& Fadel, 2009)

Ketiga konsep pelangi tersebut menjadi dasar pemikiran untuk mengaplikasikan proses pembelajaran yang inovatif. Kemampuan siswa untuk lebih mampu beradaptasi dan memiliki inisiatif dalam bekerja secara independen merupakan tujuan dari inti pertama life and career skills. Selain itu, siswa juga dibekali dengan kemmpuan untuk berinteraksi sosial secara efektif dan memiliki jiwa kepemimpian dan tanggungjawab.

Konsep kedua adalah Learning and Innovation Skills, didalamnya terdapat prinsip 4C: Critical Thinking; Communication; Collaboration; Creativity. Keterampilan tersebut disampaikan dengan konsep ke-tiga: Information Media and Technology Skills. Konsep terakhir ini merupakan konsep pembeda dari konsep-konsep pembelajaran konfensional. Disini siswa dituntut untuk mampu secara efektif dan efisien untuk mengakses informasi, mengevaluasi dan menggunakannya secara tepat. Sehingga, literasi media sangat diperlukan oleh setiap siswa. Selain itu, pengembangan media literasi sebagai dasar digunakan untuk melakukan dan menciptakan terobosan-terobosan inovatif dalam pemecahan masalah.
Serta tidak kalah penting yaitu kemampuan untuk mengkomunikasikan inovasi tersebut.

Peran guru dalam konsep ini, tidak berhenti hanya pada tataran tiga konsep di atas, tetapi lebih jauh dari itu. Selain penguasaan tiga konsep tersebut, guru abad 21 dituntut untuk mampu menciptakan Learning Environments; Professional Development; Curriculum and Instruction; Standards and Assessments. Empat konsep tambahan tersebut merupakan alat yang diperlukan untuk tercapainya tiga konsep pelangi yang harus dimiliki oleh siswa.

Peran guru dalam Industrial Age dan Knowledge Age juga sangat berbeda. Terdapat 16 perbedaan peran guru dalam perpindahan era tersebut (Trilling \& Hood, 1999). Terjadi pergeseran penerapan Pendidikan. Beberapa tujuan Pendidikan di Industrial Age justru merupakan kebalikan dari Knowledge Age. Dimana pembelajaran dengan menyampaikan informasi, latihan, tatacara pembelajaran sangat adaptif dalam Industrial Age, sekarang pembelajaran dalam bentuk projek, pemberian masalah, menemukan dan inovasi 
menjadi lebih diutamakan di Knowledge Age.

Perpindahan paradigma tersebut menjadi kendala yang pasti harus dihadapi oleh setiap pendidik. Sehingga yang terpenting dari perubahan paradigma tersebut adalah tantangan bagi guru untuk berubah secara profesional baik itu sebelum pembelajaran dilakukan (preservice), ketika pembelajaran berjalan (inservice) dan tindak lanjut setelah pembelajaran terjadi (assessment) yang merupakan perwakilan untuk setiap guru dan fungsinya dalam proses pembelajaran (Fisher et al., 1996; Sandholtz et al., 1997).

Secara

sederhana

merambahnya sistem Information and communication technology (ICT) telah mempengaruhi tidak hanya proses pembelajaran, namun termasuk didalamnya kebijakan, teori mengajar dan juga penelitian. Sehingga digital teknologi telah menjadi bagian yang tidak terpisahkan dalam pendidikan. Penggunaan laptop, tablet, telpon pintar dalam pembelajaran formal dan non-formal tidak bisa terelakan lagi, dimana hal tersebut membuka selebarlebarnya kesempatan pendidik untuk berinovasi dalam pembelajaran (Selwyn \& Facer, 2014). Salah satu contoh penerapan ICT dalam pembelajaran adalah dengan menggunakan media game komputer untuk menguasai kosa kata (Rahman \& Angraeni, 2020).

Dengan melihat perbedaan fungsi guru yang sangat komplek dan tujuan Pendidikan siswa yang lebih menantang di abad 21 ini, sudah pasti banyak hal yang menghambat proses peralihan tersebut. Contohnya, di
Malaisia, penggunaan Internet sebagai bagian dari pembelajaran bukan lagi halangan bagi guru, karena guru bisa mengaksesnya dengan menggunakan telpon pintar dan laptop. Sedangkan untuk siswa menjadi masalah, karena di sana mereka hanya bisa mengakses komputer di laboratorium komputer saja (Garba et al., 2015). Tidak jauh berbeda dari Malaysia, di Indonesia juga, penggunaan komputer di Pendidikan formal terbatas pada kesediaan komputer di laboratorium.

Selain penelitian-penelitian yang diungkapkan diatas, pemerintah Indonesia melalui Kemdikbud juga merumuskan definisi keteriampilan abad 21 yang mengedepankan tiga aspek:

1. Kualitas Karakter Siswa (Religiositas,Nasionalisme,

Kemandirian, Gotong royong, dan Integritas).

2. Keterampilan Literasi Dasar (Bahasa, Numerasi, Sains, Digital, Finansial, serta Budaya dan Kewargaan).

3. Kompetensi (Berpikir kritis, Kreativitas, Komunikasi dan Kolaborasi).

Penguasaan Keterampilan abad 21 penting baik untuk menguasai teknologi media informasi, melanjutkan pendidikan ke jenjang yang lebih tinggi, menghadapi dunia kerja, ataupun menghadapi dunia usaha.

Institusi Pendidikan formal perlu merespon hal tersebut dengan menyiapkan para peserta didiknya agar menguasai berbagai Keterampilan Abad 21. Keterampilan tersebut harus dimiliki oleh para peserta didik di 
berbagai jenjang pendidikan, agar kelak mereka mampu bertahan dan maju dalam iklim persaingan dunia. Dalam berbagai fase dan unsur kehidupan, pengusaan keterampilan ini disinyalir menjadi faktor penting penentu kesuksesan.

Demi menyiapkan peserta didik menguasai keterampilan abad 21, penting untuk mempersiapkan tenaga pendidiknya (guru), yang merupakan fasilitator pembelajaran di lapangan. Sebagai langkah awal, guru perlu memiliki wawasan tentang urgensi penguasaan keterampilan abad 21 . Kemudian, guru perlu memiliki wawasan mengenai apa saja keterampilan yang tergolong keterampilan abad 21. Setelah itu, guru perlu memiliki wawasan dan mampu menjewantahkan dalam implementasi keterampilan abad 21 di berbagai tahapan pembelajaran. Ketika guru telah siap dan mampu melaksanakan tahapan pembelajaran berbasis keterampilan abad 21, besar kemungkinan mereka akan mampu memfasilitasi siswanya untuk penguasaan keterampilan ini.

Di jenjang SMP, Pelajaran

Bahasa Inggris merupakan salah satu mata pelajaran inti yang masih diujiannasionalkan. Sebetulnya, kurikulum Bahasa Inggris SMP melalui Standar Isi dan Standar Kompetensinya telah diarahkan untuk penguasaan keterampilan abad 21. Selain itu, melihat peran Bahasa Inggris sebagai alat komunikasi global, menjadi alasan tambahan pemilihan para guru Bahasa Inggris jenjang SMP di Kabupaten Sumedang sebagai target utama untuk dikuatkan pemahaman dan kemampuannya dalam mengimplementasikan keterampilan abad 21.

Khusus untuk pembelajaran Bahasa Inggris penggunaan ICT sebagai saran pembelajaran abad 21 bisa menyediakan penutur asli Bahasa Inggris ke dalam kelas, sehingga siswa diberikan Bahasa Inggris kontekstual yang aplikatif dan alami. Berdasarkan teori dan keuntungan serta kebutuhan akan penggunaan teknologi dalam kelas, maka kompetensi guru abad 21 harus segera terpenuhi. Hal ini terjadi karena siswa sekarang banyak berinteraksi dengan menggunakan ICT, sehingga ICT seharusnya merupakan bagian dari pembelajaran di kelas juga (Kivinen et al., 2016).

Di Kabupaten Sumedang penyebaran MGMP dibagi menjadi 4 wilayah. Berdasarkan hasil observasi yang dilakukan oleh Musyawarah Guru Mata Pelajaran Bahasa Inggris Wilayah I kabupaten Sumedang, kemampuan guru Bahasa Inggris dalam mengimplementasikan proses pembelajaran abad 21 masih perlu ditingkatkan berdasarkan hasil survey awal mengenai penyusunan rencana pembelajaran Berbasis Keterampilan, Pelaksanaan Pembelajaran, serta Evaluasi Pembelajaran. Hal ini dipertegas dengan belum adanya inovasi pembelajaran yang dilakukan oleh guru Bahasa Inggris, serta peran serta siswa dalam pencapaian abad 21 yang telah ditetapkan dalam buku kurikulum 2013. Sehingga penguatan dan pendampingan guru mata pelajaran Bahasa Inggris SMP di wilayah 1 Sumedang perlu dilakukan, demi tercapainya siswa dengan kemampuan abad 21 yang utuh.

Sebagai imbasnya, penguatan 
wawasan dan kemampuan mengelola pembelajaran berbasis keterampilan abad 21 sangat diperlukan, sehingga para peserta didik dapat mengalami proses pembelajaran yang mereka butuhkan untuk menghadapi tuntutan jaman. Hal ini akan berbanding lurus dengan indeks kualitas pendidikan Bahasa Inggris di Kabupaten Sumedang secara umum, pun dengan indeks kualitas lulusan.

\section{METODE}

\section{Khalayak Sasaran}

Guru sasaran pada program ini ditentukan secara purposif menimbang keterjangkauan lokasi dan banyaknya peserta yang antusias untuk mengikuti pelatihan. Jumlah guru sasaran program ini adalah 30 orang guru bahasa inggris di wilayah 1 Kabupatan Sumedang yang mencakup: Tanjungsari, Sukasari, Pamulihan, Cimanggung, dan Jatinangor.

\section{Metode Pelaksanaan Kegiatan}

Karena Kompetensi yang hendak dicapai merupakan keseluruhan dari Keterampilan adad 21 seperti yang tertuang di bawah ini.

1. Pemahaman urgensi dan konsep dasar Keterampilan abad 21.

2. Penyusunan Rencana Pelaksanaan Pembelajaran (RPP) yang mengakomodir penguasaan peserta didik akan Keterampilan Abad 21.

3. Pelaksanaan Pembelajaran dengan pemanfaatan IT sebagai media dan moda belajar.

4. Pelaksanaan Pembelajaran terintegrasi Penguatan Pendidikan Karakter (PPK) dan Gerakan Literasi Nasional (GLN).
5. Pelaksanaan Pembelajaran berbasis Kompetensi abad 21 (Berpikir kritis, Kreativitas, Komunikasi dan Kolaborasi).

6. Macam-macam Penilaian berbasis keterampilan abad 21.

Maka ketercapaian kompetensi memerlukan proses secara berkelanjutan. Sehingga program ini hanya memberikan penguatan mengenai keterampilan abad 21 .

Oleh karena itu metode dalam pelaksanaan program pengabdian ini adalah sebagai berikut.

1. Survey awal untuk menentukan masalah yang akan dicarikan solusi.

2. Penyampaian informasi dan tanya jawab dengan format berupa Focus Group Discussion.

3. Pelaksanaan pelatian dan penguatan.

4. Pendampingan peserta setelah pelatihan.

5. Survey akhir untuk mengevaluasi efektifitas kegiatan.

\section{Pelaksanaan Kegiatan}

Proses pelaksanaannya dibagi menjadi 3 tahap yaitu tahap persiapan, pelaksanaan dan tindak lanjut. Pada tahap persiapan, penyusunan kepanitiaan, penentuan materi inti dan penentuan peserta guru sasaran dilaksanakan. Tahap ini berlangsung sampai penyusunan program dan koordinasi kesiapan.

Setelah tahap persiapan, kegiatan dilanjutkan pada tahap pelaksanaan dimana terdapat pemaparan materi dari narasumber yang kompeten, workshop penyusunan rencana pembelajaran dan kelengkapannya, serta pendampingan 
implementasi di Sekolah guru sasaran. Lalu dilanjutkan pada tahap yang terakhir yaitu tindak lanjut sebagai evaluasi program.

\section{HASIL DAN PEMBAHASAN}

Sebagai peserta guru sasaran ditentukan 30 orang guru mata pelajaran Bahasa Inggris Jenjang SMP, baik negeri maupun swasta. Guru sasaran berdinas di wilayah Kabupaten Sumedang dan tergabung dalam Musyawarah Guru Mata Pelajaran Bahasa Inggris SMP Wilayah I Sumedang. Wilayah I Sumedang mencakup: Kecamatan Tanjungsari, Sukasari, Pamulihan, Cimanggung, dan Jatinangor.

Keikutsertaan pada program ini bersifat voluntary. Ketiga puluh orang guru sasaran yang terlibat dalam program ini adalah individu-individu yang sama sejak awal hingga akhir kegiatan.

Berdasarkan analisis situasi dan permasalahan yang telah disebutkan di atas, maka tujuan dari Pengabdian kepada Masyarakat ini antara lain:

1. Memberikan wawasan tentang Keterampilan Abad 21 Kepada Guru Sasaran.

2. Menfasilitasi Pembelajaran implementasi berbasis Keterampilan Abad 21 Kepada Guru Sasaran.

3. Memberikan pendampingan dalam melaksanakan pembelajaran tahapan Keterampilan Abad 21.

4. Mempersiapkan Guru Sasaran untuk dapat memfasilitasi Peserta didik dalam usaha menguasai keterampilan Abad 21.
Adapun deskripsi hasil pelaksanaan kegiatan ini dibagi menjadi:

1. Tahap Persiapan

Pada tahap ini dilakukan penyusunan materi pelatihan dan penyebaran survey untuk mengetahui tingkat urgensi program ini.

\section{Tahap Pelaksanaan}

Kegiatan pengabdian ini dilakukan dimulai pada tanggal 9 Juli 2020 dan berakhir pada 28 Juli 2020 dengan melakukan tiga kali pembekalan dan tiga kali workshop. Program dibagi menjadi tiga kali penguatan dan tiga kali workshop. Tingkat kehadiran peserta rata-rata pada pelaksanaannya mencapai 92,73 $\%$.

Keberhasilan pencapaian pelatihan ini bisa dideteksi dari antusiasme peserta untuk hadir pada pelatihan tersebut. Persentase jumlah peserta yang hadir disetiap pertemuan.

Antusiasme peserta untuk menghadiri pelatihan tersebut tidak kurang dari 93\%. Sehingga bisa dikatakan bahwa pendalaman pengetahuan mengenai pengajaran di abad 21 sangat diminati oleh para guru.

\section{Tahap Evaluasi \\ Ketercapaian dari sasaran solusi} untuk empat masalah yang telah diungkapkan di atas dievaluasi dengan menggunakan angket dengan hasil seperti pada tabel 1 . 
Tabel 1. Tingkat Kebermanfaatan Pelatihan

\begin{tabular}{ccccc}
\hline \multirow{2}{*}{ No. } & \multicolumn{1}{c}{ Kategori dalam persen } & \\
\cline { 3 - 5 } & $\begin{array}{c}\text { Sangat } \\
\text { bermanfaat }\end{array}$ & Bermanfaat & $\begin{array}{c}\text { Kurang } \\
\text { bermanfaat }\end{array}$ & $\begin{array}{c}\text { Tidak } \\
\text { bermanfaat }\end{array}$ \\
\hline $\mathbf{1}$ & $\begin{array}{l}\text { Memberikan wawasan tentang } \\
\text { Keterampilan Abad 21 Kepada Guru } \\
\text { Sasaran }\end{array}$ & $93 \%$ & $7 \%$ & \\
\hline $\mathbf{2}$ & $\begin{array}{l}\text { Menfasilitasi implementasi } \\
\text { Pembelajaran berbasis Keterampilan } \\
\text { Abad 21 Kepada Guru Sasaran }\end{array}$ & $87 \%$ & $13 \%$ & \\
\hline $\mathbf{3}$ & $\begin{array}{l}\text { Memberikan pendampingan dalam } \\
\text { melaksanakan tahapan pembelajaran } \\
\text { berbasis Keterampilan Abad 21 }\end{array}$ & $87 \%$ & $10 \%$ & $3 \%$ \\
\hline $\mathbf{4}$ & $\begin{array}{l}\text { Mempersiapkan Guru Sasaran untuk } \\
\text { dapat memfasilitasi Peserta didik dalam } \\
\text { usaha menguasai keterampilan Abad 21 }\end{array}$ & $93 \%$ & $7 \%$ & \\
\hline
\end{tabular}

Berdasarkan tabel 1. kegiatan pelatihan ini sangat memberikan manfaat sebagai penunjang pengembangan kompetensi guru, terutama untuk kategori pemberian wawasan tentang keterampilan Abad 21 dan persiapan guru sasaran untuk memfasilitasi peserta didik. Kedua aspek tersebut mendapatkan apresiasi sebesar 93\%. Begitu juga dengan implementasi pembelajaran dan pemberian pendampingan, walaupun tidak sebesar kedua aspek sebelumnya dengan apresiasi 87\% untuk keduanya. Namun khusus untuk pendampingan, ada $3 \%$ guru sasaran yang menganggap kurang bermanfaat.

Penyampaian materi serta prosedur pelaksanaan juga dianggap sudah cukup baik sehingga hasil dari pengabdian ini sangat terukur. Berdasarkan kondisi-kondisi tersebut maka bisa disampaikan bahwa pelatihan ini memberikan manfaat yang cukup memuaskan selama pelatihan berlanjut. Sehingga guru sasaran bisa lebih meningkatkan kapasitas diri untuk mengikuti era pembelajaran di abad 21 .

\section{KESIMPULAN}

Sesuai dengan hasil yang diperoleh maka dapat disimpulkan bahwa Pelatihan Pembekalan dan Implementasi Pembelajaran Abad 21 bagi Guru Bahasa Inggris SMP Kabupaten Sumedang berdasarkan hasil survey memberikan manfaat dan pengaruh yang untuk pengembangan kapasitas guru sasaran. Namun efektifitas secara keseluruhan karena kemampuan pengembangan keterampilan abad 21 merupakan sebuah proses yang berkelanjutan dan hasil yang inginkan akan sangat bergantung pada kemauan and keinginan guru tersebut untuk tetap mengembangkan diri mengikuti era abad 21.

\section{DAFTAR PUSTAKA}

$\mathrm{Au}, \mathrm{W}$. (2011). Teaching under the new Taylorism: high-stakes testing and the standardization of the 21 stcentury curriculum Journal of Curriculum Studies, 43(1), 25-45.

https://doi.org/10.1080/0022027 2.2010.521261 
Jurnal Widya Laksana, Vol.10, No.2, Agustus 2021

BNSP. (2010). Laporan BSNP Tahun 2010. Badan Standar Nasional Pendidikan.

Fisher, C., Dwyer, D. C., \& Yocam, K. (1996). Education \& Technology: Reflections of Computing in Classrooms. Jossey-Bass.

Garba, S. A., Yusuf, B., \& Busthami, A. H. (2015). Toward the Use of Technology and 21st Century Teaching-learning Approaches: The Trend of Development in Malaysian Schools within the Context of Asia Pacific. International Journal of Emerging Technologies in Learning (iJET), 10(4). https://doi.org/10.3991/ijet.v10i4 .4717

Kemdikbud. (2013). Penyelenggaraan Pendidikan Sistem Ganda pada Sekolah Menengah Kejuruan. Direktorat Pendidikan Menengah Kejuruan.

Kivinen, O., Piiroinen, T., \& Saikkonen, L. (2016). Two viewpoints on the challenges of ICT in education: knowledge-building theory vs. a pragmatist conception of learning in social action. Oxford Review of Education, 42(4), 377-390. https://doi.org/10.1080/0305498 $\underline{5.2016 .1194263}$
Rahman, A. A., \& Angraeni, A. (2020). Empowering Learners with Role-Playing Game for Vocabulary Mastery. International Journal of Learning, Teaching and Educational Research, 19(1). https://doi.org/10.26803/ijlter.19. 1.4

Sandholtz, J. H., Ringstaff, C., \& Dwyer, D. C. (1997). Teaching with Technology: Creating Student-Centered Classrooms. Teacher's College Press.

Selwyn, N., \& Facer, K. (2014). The sociology of education and digital technology: Past, present and future. Oxford Review of Education(40), 482-496.

Simin, G., Ahmad, Z. A., Muhammad, F. A., Ng, R. Y., Yao, M., \& Zhang, T. (2014). Integration in education: incorporation of teaching and learning improvement. The Malaysian Online Journal of Educational Technology, 2, 24-54.

Trilling, B., \& Fadel, C. (2009). 21st Century Skills: Learning for Life in Our Times. John Wiley \& Sons.

Trilling, B., \& Hood, P. (1999). Learning, Technology, and Education Reform in the Knowledge Age. WestEd Educational Technology. 